\title{
MUDANÇAS INCREMENTAIS E SEUS IMPACTOS SOBRE A QUALIDADE: O ESTUDO DE CASO DA EMPRESA K DE ASSISTÊNCIA TÉCNICA DE PRODUTOS MÉDICO- HOSPITALARES.
}

\author{
Laura Najla Paschoal Quirilos Assis \\ Thalita Toshie de Jesus Sibuya
}

\begin{abstract}
Resumo
O presente artigo apresenta ponderações de um estudo de caso em uma Empresa de Assistência Técnica de Produtos Médicos Hospitalares. Com o objetivo de analisar por que, como e quais foram os resultados da mudança incremental sobre a qualidade. A metodologia utilizada está baseada em estudo de caso fazendo uso de entrevistas não estruturadas e técnicas de observação. É discutido no presente artigo o conceito de qualidade de serviços, bem como as dificuldades para a implantação de uma mudança organizacional, ocasionada pela mudança incremental. Observa-se a melhoria da qualidade de serviço quando a mudança incremental é bem sucedida. Porém, é mister a conquista das mudanças, pois a qualidade de serviço é subjetiva e está baseada, normalmente, na percepção do cliente.

Palavras-chaves: Mudança incremental, qualidade em Serviços, mudança organizacional.

Abstract

This paper presents considerations of a case study in a Technical Assistance Company of Hospital Medical Products. In order to analyze why, how and what were the results of incremental change over quality. The methodology is based on a case study with the usage of unstructured interviews and observation techniques. The present article discusses the concept of quality of services as well as the difficulties in the implantation of an organizational change, caused by incremental change. The improvement of the quality of service is noticed when the incremental change is successful. However, it is important to preserve the achievements of the changes because the quality of service is subjective and it is usually based on the customer's perception.
\end{abstract}

Keywords: Incremental change, service quality, organizational change.

\section{Resumen}

Este artículo presenta las consideraciones de un estudio de caso en una Empresa de asistencia técnica de productos médica y hospitalaria. Con el objetivo de analizar por qué, cómo y cuáles fueron los resultados del cambio incremental sobre la calidad. La metodología se basa en un estudio de caso haciendo uso de entrevistas no estructuradas y técnicas de observación. Se analiza en este artículo el concepto de calidad de servicio, así como las dificultades en la implementación de un cambio organizacional, causado por el cambio incremental. Nota la mejora de la calidad de servicio cuando el cambio incremental es exitosa. Sin embargo, es esencial para la consecución del 
cambio debido a la calidad del servicio es subjetiva y se basa por lo general en la percepción del cliente.

Palabras clave: cambio incremental, la calidad los servicios, el cambio organizacional.

\section{INTRODUÇÃO}

A empresa $K$ de assistência técnica de equipamentos médicohospitalares está passando por uma mudança incremental no processo de recebimento dos equipamentos para manutenção. No ano de 2012, com objetivo de garantir a rastreabilidade e aumentar a qualidade dos serviços prestados, foi instituída uma mudança no processo de recebimento de equipamentos para manutenção. Observavam-se reclamações dos clientes internos e externos sobre a localização dos equipamentos admitidos na empresa $\mathrm{K}$ e se os mesmos haviam sido consertados ou não.

Mudanças incrementais segundo Nadler e Thushman (1955), são pequenas e acontecem nos períodos de equilíbrio da organização, promovem uma continuidade ajustando os componentes de estratégia, estrutura, pessoas e processos. Contudo, a cultura de uma organização é composta de características relativamente estáveis o que a torna muito resistente à mudança, Robbins (2000) corrobora tal perspectiva.

Para Karl Albrecht (1992), qualidade em serviços é a capacidade que uma experiência ou qualquer outro fato tenha para satisfazer uma necessidade, resolver um problema ou fornecer benefícios a alguém. Juran (1992, p. 8) descreve o cliente como "qualquer pessoa que seja impactada pelo produto ou processo", classificando-o como externo (impactado pelo processo, mas não pertencente à empresa) e interno (impactado pelo processo e membro da empresa). Ressalta-se ainda que os serviços possuam dois comportamentos de qualidade que devem ser considerados: o serviço propriamente dito e a forma como esse é percebido por quem o recebe. Assim, a qualidade pode cooperar para que mudanças incrementais concorram para o aperfeiçoamento de serviços.

De acordo com Schmenner (1999), a intangibilidade no setor de serviços é como algo que não podemos tocar ou sentir, ou seja, é impossível fazer estoque. Por sua natureza, o consumo de um serviço costuma ser quase simultâneo a sua produção. Portanto, tal intangibilidade é percebida pelo 
consumidor como referencial de qualidade: quanto melhor o serviço, melhor sua qualidade. Possivelmente tal empresa se torne excelente, porque se aperfeiçoou (mudou) com o tempo.

\section{MARCO TEÓRICO}

O presente marco teórico delineia as principais contribuições da literatura na construção do lastro acadêmico do presente trabalho. Nesse sentido, primeiramente se busca aprofundar a temática da mudança organizacional para que se possa dar o fulcro de como as alterações incrementais agem sobre a qualidade nas organizações e logo em seguida se aborda a temática da qualidade em serviços já que a Empresa $\mathrm{K}$ atua na área de serviços, como se vê a seguir.

\subsection{MUDANÇA ORGANIZACIONAL}

Mudanças constantes nos cenários econômico, institucional e tecnológico, somadas à competição global tem transformado a estrutura das organizações, em conformidade com Castells (1999). O que ocorre no ambiente externo à organização ressoa em seu ambiente interno na busca da homeostase funcional de suas estruturas funcionais; até porque organizações podem ser vislumbradas como sistemas abertos que agem, reagem e interagem com o ambiente em que estão inseridas.

Assim, as organizações são ao mesmo tempo resultado e resposta às mudanças de seu ambiente externo, mas são igualmente as alterações que fazem em si mesmas de forma independente das alterações de seu ambiente no sentido de se anteciparem a mudanças que ocorrem (ou que ocorreram) que, melhor se adaptando, possam mais facilmente atingir o sucesso o se sustentarem em posições bem sucedidas.

Fleury (1993) corrobora tal percepção ao discutir a cultura da qualidade e as mudanças culturais de organizações industriais. De fato, a autora traça um pano de fundo que permite se visualizar o quanto pode haver uma relação plurívoca, de vários significados, entre o desenvolvimento da cultura organizacional e a implementação de programas, filosofias ferramentas afetas à qualidade em organizações industriais. 
Em um estudo sobre mudança organizacional Lima e Bressan (2003) exploram algumas definições de pesquisadores que aqui se reproduzem no sentido de se explorar qual seja o entendimento sobre Mudança Organizacional:

\section{QUADRO 1}

\begin{tabular}{|c|c|}
\hline Autor & Definição \\
\hline Bruno-Faria (2003) & $\begin{array}{l}\text { Trata-se de toda alteração, planejada } \\
\text { ou não, ocorrida na organização, } \\
\text { decorrente de fatores internos e/ou } \\
\text { externos à mesma, } \\
\text { que traz algum impacto nos } \\
\text { resultados e/ou nas relações entre as } \\
\text { pessoas no trabalho. }\end{array}$ \\
\hline Nadler et all (1994) & $\begin{array}{l}\text { Defendem que a mudança } \\
\text { organizacional é a resposta frente às } \\
\text { transformações que permeiam om } \\
\text { ambiente, com intuito de manter a } \\
\text { igualdade entre os componentes } \\
\text { organizacionais (trabalhos, pessoas, } \\
\text { arranjos/ estruturas e cultura). }\end{array}$ \\
\hline Porras e Robertson (1992) & $\begin{array}{l}\text { Conjunto de teorias, valores, } \\
\text { estratégias e técnicas cientificamente } \\
\text { embasadas a fim de uma mudança } \\
\text { planejada do ambiente de trabalho } \\
\text { com objetivo de elevar } \\
\text { desenvolvimento individual e } \\
\text { desempenho organizacional. }\end{array}$ \\
\hline Araújo (1982) & $\begin{array}{l}\text { Transformação significativa, } \\
\text { articulada, planejada e e } \\
\text { operacionalizada por pessoal interno } \\
\text { ou externo à organização, que tenha } \\
\text { apoio da alta administração e atinja } \\
\text { de forma integrada os aspectos } \\
\text { comportamental, } \\
\text { tecnológico e estratégico. estrutural, }\end{array}$ \\
\hline
\end{tabular}

Fonte: Adaptado de Lima e Bressan (2003, p. 23).

Percebe-se, então, que Mudança organizacional é a um só tempo tanto uma prática organizacional fundamentada em princípios estruturados em ciência e em tecnologia como arcabouço prescritivo para que as organizações atinjam objetivos previamente estabelecidos como também um conjunto de 
saberes formais que descrevem esta variação organizacional no tempo.

Lima e Bressan (2003, p. 25) sugerem o seguinte conceito para mudança organizacional:

“...qualquer alteração, planejada ou não, nos componentes organizacionais - pessoas, trabalho, estrutura formal, cultura - ou nas relações entre organizações e seu ambiente, que possam ter consequências relevantes, de natureza positiva ou negativa, para eficiência, eficácia e/ou sustentabilidade organizacional."

As organizações, vistas sob tal prima, são entes orgânicos que se alteram no tempo, fisiologicamente, adaptando-se ao meio em que estão inseridas para que continuem a existir e igualmente alterar o meio em que se inserem para que esse lhe seja mais propício.

Nadler et all (1995) relatam dois tipos de mudança: a incremental/contínua e a descontínua. A mudança incremental ou contínua ocorre dentro dos limites da organização sem representar uma ruptura dos padrões existentes. Já a mudança descontínua é caracterizada por romper padrões, desencadeando novas estruturas, estratégias, processos, pessoas e tecnologias. Nesse último contexto há uma reação a eventos desestabilizadores do ambiente.

Lima e Bressan (2003, p. 25) reforçam o conceito acima quando afirmam que a mudança incremental "altera apenas alguns aspectos da organização, faz pequenos ajustes continuamente e ocorre em situações em que o ambiente é mais estável".

As autoras ressaltam que a mudança descontínua não deve ser evidenciada como um conjunto de mudanças incrementais, que levam a uma grande mudança organizacional. "Pois, ambas - mudança descontínua e incremental - são qualitativa e essencialmente diferentes". (LIMA; BRESSAN, 2003, p. 26).

Para os autores Porras e Robertson (2003) há uma distinção entre mudanças de primeira e de segunda ordem. O primeiro tipo representa uma mudança linear e contínua concebida por alterações nas características dos sistemas, porém não alteram aspectos chaves da organização. O segundo tipo 
trata-se de uma mudança multidimensional e radical que quebra paradigmas da organização.

Dentro dessa perspectiva, Weick e Quinn (1999) classificam em dois os tipos de mudança organizacional: contínua e episódica. A mudança contínua é constante e evolutiva exemplificadas por pequenos avanços na rotina da empresa. A mudança episódica é infrequente e intencional, ocorre em períodos de divergência, quando a organização encontra-se em desequilíbrio.

Para Mintzberg et all (2003) afirmam que mudança incremental é de fácil implantação e promove a integração entre estratégia, estrutura, pessoas e processos, pois "o sistema geral se adapta, mas não é transformado". (MINTZBERG et all, 2003, p. 161).

Os autores ainda propõem um roteiro comum para implantação de mudanças incrementais que se inicia com:

“... ampla aceitação da necessidade de mudança, abertura para possíveis alternativas, exame objetivo dos prós e contras de cada alternativa plausível, participação daqueles diretamente afetados pela análise precedente, um teste de mercado ou operaçãopiloto quando viável, tempo para aprender novas atividades, modelos de papéis estabelecidos, recompensas conhecidas para o sucesso positivo, avaliação e refinamento" (MINTZBERG et all, 2003, p. 160).

Ressalta-se que a mudança incremental é facilitadora para o sucesso, pois reduz riscos à medida que incrementos pequenos incorrem em riscos menores. Os autores acima citados afirmam que em períodos convergentes (de mudanças incrementais) as estruturas e sistemas organizacionais tornam-se tão interligados que permitem apenas mudanças compatíveis. Os funcionários, com o tempo, desenvolvem hábitos que se transformam em comportamentos padronizados e em valores.

Conforme segue abaixo:

"...Os modelos que auto-reforçam comportamento, normas e valores contribuem para aumentar o ímpeto e a complacência organizacional e, com o tempo, para um senso de história organizacional. Essa história organizacional - exemplificada por histórias, heróis e padrões comuns - especifica "como trabalhamos aqui" e 
"o que é considerado importante aqui" (MINTZBERG et all, 2003, p. 161).

Mudanças incrementais levadas a cabo com eficiências alteram o comportamento dos sujeitos que compõem a organização, de modo que estes se imbuem das conquistas que a mudança traz como um valor inquestionável na organização.

Outro viés que deve ser considerado para o entendimento da mudança organizacional é a perspectiva da cultura organizacional. Assim, Ott apud Lima e Bressan (2003, p. 34) esclarecem que a cultura organizacional:

\footnotetext{
“...é a cultura que existe em uma organização (...) similar à cultura de uma sociedade e consiste de valores, crenças, premissas, percepções, normas, artefatos e padrões de comportamento. É a força invisível e inobservável que está sempre por trás das atividades organizacionais que podem ser vistas e observadas (...) é a energia social que move as pessoas a agirem (...) funciona como um mecanismo de controle organizacional, aprovando ou proibindo comportamentos, de modo informal."
}

A cultura organizacional é o objeto transformador em um processo de mudança. Mas, lembram que é um requisito para mudanças radicais ou descontínuas. Contudo, podem ser também necessárias em processos de mudança incremental, de grande abrangência e que comprometem principalmente o trabalho dentro de uma organização.

$\mathrm{Na}$ área de prestação de serviços, como se verá a seguir, a mudança se faz necessária cada vez mais no sentido em que garante a qualidade de sua prestação; conforme segue:

\subsection{QUALIDADE EM SERVIÇOS}

Moraes (2010) conceitua qualidade por várias noções de excelência, valor, especificações, conformidade, regularidade, adequação ao uso e satisfação. Para Fitszmmons e Fitszmmons (2000), os serviços caracterizamse pelo encontro entre fornecedor e cliente em que o último participa ativamente no processo de produção do serviço e segue uma tríade a qual 
demonstra a relação entre a organização de serviço - cliente - pessoal da linha de frente e seus possíveis conflitos.

Pelo que se pode vislumbrar o serviço gera no cliente uma noção de excelência, valor, especificações, conformidade, regularidade, adequação ao uso e satisfação.

Observa-se também que o produto final de um serviço é sempre um sentimento, os clientes ficam satisfeitos ou não, conforme suas expectativas. Portanto, a qualidade do serviço é variável de acordo com o tipo de pessoa e, segundo Karl Albrecht (1992), a qualidade em serviços é "uma situação na qual uma organização fornece a qualidade e serviços superiores aos seus clientes, proprietários e funcionários". Slack et all (1997) afirmam que ao basear a qualidade em expectativas existe o problema de que a expectativa pode variar dependendo de quem recebe o serviço/ produto.

Grönroos (2004) relata que o cliente ao adquirir um serviço, faz uma avaliação de dimensões técnica e funcional. Técnica porque se relaciona ao desempenho e funcional, pois está ligada ao tempo e ao atendimento. Portanto, trata-se de percepção, resultando em uma variável de pessoa a pessoa: a qualidade. Reiterando, a qualidade percebida é o resultado da diferença entre a expectativa do cliente e o seu julgamento sobre 0 desempenho do serviço, em relação a uma série de características, algumas técnicas e outras funcionais.

Segundo Peters e Austin (1994), um cliente mal atendido terá um efeito multiplicador extremamente nocivo para a organização, na medida em que ele disseminará seu descontentamento para sua família, seus amigos e outras pessoas com quem entre em contato em uma proporção maior daquela atingida pelo cliente satisfeito.

A qualidade de uma empresa apresenta um grande número de variáveis a serem verificadas, essas variáveis interferem na qualidade final do produto ou serviço. Segundo Paladini (2008) as variáveis que interferem na qualidade requerem uma análise permanente, pois sempre há novos elementos surgindo no ambiente.

Algumas das variáveis que podem ser verificadas em uma prestadora de serviço, de acordo com Zeithaml e Berry (1985), são: acessibilidade, 
competência, comunicação, confiabilidade, cortesia, credibilidade, rapidez de resposta, segurança entre outras.

Como as variáveis acima, as fontes de erros são intermináveis em uma prestadora de serviços. Porém Schmenner (1999) diz que para zero reclamação, uma empresa de assistência técnica, deve eliminar os erros e para que isso ocorra deve existir mudança de atitudes dentro da empresa.

Fitszmmons e Fitszmmons (2000) relacionam a não qualidade do serviço à falência das organizações. Sublinham que os consumidores já não mais toleram serviços impessoais, produtos com defeito e promessas não cumpridas. Os autores alertam que os produtos defeituosos podem ser trocados ou devolvidos, mas a quem os clientes poderão recorrer no caso dos serviços apresentados com falhas? Uma alternativa para essa questão é o judiciário. Nenhum serviço é imune a um processo e esse pode resultar em vários aspectos negativos, tais como, a perda da imagem da organização e de elevadas somas monetárias.

Ainda sobre o poder judiciário, não se pode deixar de comentar, que no Brasil, há o Código de Defesa do Consumidor, segundo IDEC (Instituto Brasileiro de Defesa do Consumidor) (2013), trate-se de uma lei abrangente que aborda as relações de consumo em todas as esferas, definindoresponsabilidades, mecanismos, reparação de danos causados bem como a punição dos mesmos.

Para se refletir a qualidade em serviços nas organizações é necessário que a alta direção esteja comprometida com a mesma. Sendo assim, Fitszmmons e Fitszmmons (2000) adaptaram a contabilidade de custos da qualidade defendida por Juran - para convencer a alta administração da necessidade de levar a sério assuntos relacionados à qualidade - para o setor de serviços e sugeriram que esses custos fossem agrupados nas categorias de prevenção, detecção, falha interna e falha externa.

Assim, definem os autores, "correspondente à prevenção, o recrutamento e a seleção de pessoal de serviço são uma forma de evitar a má qualidade" (FITSZMMONS; FITSZMMONS, 2000, p. 155). Já a detecção é equivalente à inspeção do produto, dessa forma, pode ser caracterizada como uma reunião de dados da qualidade com intuito de verificar a condição de um serviço em relação à conformidade ao padrão. A falha interna relaciona-se aos 
custos para corrigir um trabalho que não está em conformidade com serviço proposto. E, a falha externa, aos custos para correção do serviço já prestado ao cliente.

O serviço é uma experiência para o cliente e qualquer falha pode se transformar em uma história que o cliente propagará a outros, trazendo como retorno perda significativa de futuros negócios. Tal afirmativa defendida Fitszmmons e Fitszmmons (2000), requer que as empresas pensem em agir preventivamente e melhorar continuamente a forma de prestação de serviços. Las Casas (1997) relaciona à prestação de serviços ao desempenho humano e à qualidade desse desempenho, portanto, para o autor "o ato de aperfeiçoar serviços é aperfeiçoar desempenho humano, o que é possível, principalmente, através do treinamento" (LAS CASAS, 1997, p. 116).

Juran (1992), no entanto, propõe um gerenciamento da qualidade, intitulado pelo próprio autor como "Triologia de Juran" e segue as seguintes etapas:

i. Planejamento da qualidade - o desenvolvimento de produtos e processos necessários para a satisfação das necessidades dos clientes.

ii. Controle da qualidade - busca avaliação do desempenho real da qualidade comparando com metas estabelecidas e agindo em cima das diferenças.

iii. Melhoramento da qualidade - elevar o desempenho da qualidade promovendo a infraestrutura necessária, identificando as necessidades específicas e a responsabilidade dos envolvidos para que seja bem sucedida.

Juran (1992) explica que esse processo deve ser um facilitador para que a equipe envolvida seja capaz de diagnosticar as causas estimulando soluções e controles para manutenção do resultado obtido.

Paladini (2009) ressalta que o conceito de melhoria contínua é redundante, pois não existe melhoria que não seja continua, visto que o termo 
"trata-se de uma ação constante, crescente e organizada" (PALADINI, 2009, p. 39).

Deming apud Fitszmmons e Fitszmmons (2000) fundamenta a melhoria contínua em um tripé:

- Satisfação do cliente: representa a atitude de colocar o cliente em primeiro lugar, colocando essa afirmação como filosofia e razão de ser de cada membro da organização.

- Gerenciamento por fatos: deve-se coletar e apresentar dados objetivos à gerência para auxiliar na tomada de decisão.

- Respeito pelas pessoas: estabelecimento de um programa de melhoria da qualidade, o qual abranja toda organização e incentive e motive a participação dos empregados no desenvolvimento de ideias.

A fim de mensurar o desempenho do processo e de suas atividades é importante constituir indicadores de desempenho. Tratam-se de parâmetros e critérios de avaliação "previamente estabelecidos que permitam a verificação da realização, bem como da evolução da atividade ou do processo na empresa ou negócio", corroborando Oliveira (2011, p. 152) a fundamentação de Deming.

\section{METODOLOGIA}

Este estudo se pautou em um estudo de caso. Estudo de caso segundo Yin apud Moraes (2007) "é uma forma de se fazer pesquisa empírica que investiga fenômenos contemporâneos, dentro de seu contexto de vida real, em situações sem que as fronteiras entre o fenômeno e o contexto não estão claramente estabelecidas, onde se utiliza múltiplas fontes de evidência".

A coleta de dados o artigo foi baseado em entrevistas não estruturadas e a técnica de observação proposta por Selletiz (1987); a observação se traduz em uma técnica científica ao passo em corresponde às necessidades que se impõem em função de um objetivo de pesquisa que tenha sido estabelecidado. Ademais, para ser eficaz em seu propósito, tal técnica há de ser planejada de forma sistematizada e há de estar associada a termos gerais do paradigma de 
pesquisa utilizado no esforço de conhecimento que se realiza, o qual pode ser verificado em replicação sob as mesmas condições - indo, por isso, além do se elencar curiosidades.

Quanto à observação o pesquisador deve estar atento a tudo o que diz respeito à sua suposição e não apenas selecionar o que lhe permita confirmála. No espírito de Lakatos (2001), o observador enfrenta mais dificuldades para manter a objetividade por influenciar e ser influenciado pelo grupo, e, pelas diferenças de referência entre observador e observado.

Malhotra (2005) por outro lado, em seu trabalho alerta que a principal desvantagem desde método é a tendenciosidade do observador no registro das informações.

\section{O ESTUDO DE CASO}

\subsection{A EMPRESA K}

A Empresa $\mathrm{K}$ foco desse estudo de caso, atua como representante comercial e de assistência técnica de equipamentos médico-hospitalares. Classificada, segundo SEBRAE (2013), como de pequeno porte, situada no município de Curitiba no Estado do Paraná, possui atualmente uma força de trabalho de 11 funcionários e atua no mercado há aproximadamente 25 anos. Inicialmente, trabalhava apenas como representações, porém há nove anos constituiu-se em empresa de assistência técnica, sendo que nos últimos três anos houve crescimento de 10 vezes faturamento somente para área de assistência técnica. Essa mudança levou a necessidade de ocorrerem mudanças incrementais.

A Empresa $\mathrm{K}$ detém a exclusividade na manutenção de equipamentos de alta complexidade, tais como ventiladores para manutenção de pacientes com insuficiência respiratória, incubadoras, câmeras de resfriamentos para produtos derivados do sangue e vacinas.

São clientes da Empresa $\mathrm{K}$ os principais e maiores hospitais do estado do Paraná: Hospital de Clinicas do Paraná, Hospital Universitário de Londrina, Hospital da Cruz Vermelha do Paraná, Hospital Santa Cruz, Hospital Zilda Arns bem como Prefeituras de Curitiba, Araucária, Colombo, Londrina, e não se pode deixar de citar o SESA (Secretaria do Estado de Saúde do Paraná). 


\subsection{RELATOS DA OBSERVAÇÃO}

Em agosto de 2013 foi instituído que qualquer produto que fosse admitido na Empresa $\mathrm{K}$ deveria ter uma ordem de serviço (OS). Segundo o funcionário $O$, essa OS existia na empresa, porém era realizada exclusivamente para equipamentos que tinham chamados abertos pelos próprios fabricantes com intuito de serem solicitados reparos; funcionavam como protocolo de rastreabilidade.

Segundo funcionário $\mathrm{O}$, a mudança incremental surgiu da necessidade de rastreabilidade do equipamento na assistência técnica da Empresa $\mathrm{K}$, pois

“... tínhamos problemas na identificação dos equipamentos, não sabíamos se estavam ou não na empresa, não havia rastreabilidade, porque não existia controle na entrada do equipamento aqui na empresa, observamos essa lacuna e com o aval da diretoria adotamos a ordem de serviço...".

Ainda de acordo com o funcionário $\mathrm{O}$, "tínhamos que procurar $\mathrm{O}$ equipamento aqui na empresa e, muitas vezes, já até havíamos o consertado e não sabíamos quem era do cliente que nos ligou pedindo informações sobre $o$ andamento do conserto!".

De 01 de dezembro de 2012 a 21 de janeiro de 2013 foram observadas as entradas dos equipamentos na assistência técnica da Empresa $\mathrm{K}$ e, se realmente ocorria a rastreabilidade deles através do uso da OS. Esses equipamentos chegavam à assistência técnica da empresa por meio de transportadoras, ou entregues pelos próprios clientes, ou ainda retirados pelos vendedores técnicos de Empresa $\mathrm{K}$ em seu local de origem.

Observou-se nesse período que as ordens de serviços eram realizadas, mas não para todos os produtos e nem todos os funcionários da assistência técnica da empresa $\mathrm{K}$ faziam.

Quando foram questionados sobre por que nem todas as ordens de serviço eram realizadas, relataram:

"Dá muito trabalho fazer a OS!" (Funcionário M)

"Esse equipamento não sou eu quem arruma." (Funcionário T) 
"Não precisa disso, é só mais papel." (Funcionário M)

Verificou-se a mudança incremental do produto admitido durante 0 recebimento das ligações dos clientes. Esses procuravam saber se 0 equipamento estava pronto, ou ao contrário, qual seria a previsão, visto que tinham urgência na manutenção de equipamentos essenciais para área médico-hospitalar. Após a mudança, o cliente tinha uma previsibilidade do retorno o equipamento mais facilmente.

A OS permitia a qualquer funcionário informar com exatidão e prontidão se o equipamento estava pronto e qual seria a data para retirá-lo. Todavia, houve resistência à mudança por parte de alguns funcionários; a OS não era executada. O cenário inicial voltou a imperar: sem prazos, sem rastreabilidade, sem a satisfação do cliente. Novamente o cliente frustrou-se com o serviço recebido tendo contato com a experiência negativa.

$\mathrm{E}$, quando questionados, os funcionários da assistência técnica da Empresa $\mathrm{K}$ respondiam:

\footnotetext{
"Esse equipamento não é de minha responsabilidade." (Funcionário $\mathrm{M}$ )

"Quem recebeu o equipamento não fui eu." (Funcionário T)

"Tem que ligar para o Técnico $X$ que esta em cliente para ver se ele sabe onde esta o equipamento e se o mesmo foi consertado." (Funcionário $\mathrm{O}$ ) "Quando eu chegar na empresa eu procuro o equipamento." (Funcionário A) "O técnico y pegou o equipamento e sumiu com ele." (Funcionário $\mathrm{A}$ )

"Para que fazer OS desse equipamento? Ele não tem chamado." (Funcionário T)

"Quando eu tiver tempo eu vejo onde esta o equipamento, ai eu faço uma OS." (Funcionário M) "Ninguém cobra a OS mesmo." (Funcionário M).
}

Tal perspectiva denota fortemente o estado do processo administrativo afeito ao relato; isto é, com a empresa por meio do comportamento de seus funcionários agia e reagia no contexto relatado - sem atribuir a importância necessário à execução da atividade para que o atendimento ao consumir pudesse se dar com a excelência desejada. 


\section{CONCLUSÃO}

Através da observação percebeu-se que a mudança incremental impacta na qualidade do serviço prestado.

Após a implantação da mudança incremental, a execução da ordem de serviço (OS) no momento de entrada de equipamentos para manutenção na Empresa K, observou-se a queda das reclamações dos clientes. A OS possibilitou uma eficácia extraordinária quanto resposta imediata dada aos clientes. Isso ocorreu devido à preocupação com a qualidade do serviço prestado, ilustrando que o aspecto da qualidade envolve a qualidade percebida, bem como a qualidade real.

A construção do relacionamento com 0 cliente passa pela intangibilidade, portanto o cliente "sente" o serviço recebido e esse "sentir" o leva ao encontro com a experiência da qualidade.

$\mathrm{Na}$ Empresa $\mathrm{K}$ a mudança incremental apresentou resultados positivos mesmo não seguindo as etapas iniciais para implantação de mudanças incrementais, conforme sugeriram Mintizberg et all (2003).

Porém, na Empresa $\mathrm{K}$ essa mudança contínua sofreu variação: a resistência de alguns funcionários. Essa afirmativa reitera Ott apud Lima e Bressan (2003) quando salientam que a cultura organizacional deve ser compreendida para que haja a mudança organizacional, pois ela "é a energia social que move as pessoas a agirem", atuando como "mecanismo de controle organizacional", "aprovando ou proibindo comportamentos".

Ainda que Nadler e Tushman (1955) digam que as mudanças aconteçam em momentos de equilíbrio, na Empresa $\mathrm{K}$ essa mudança ocorreu em um período de transformação, pois essa organização se adapta ao aumento de demanda de serviço. Entretanto, a mudança incremental, a implantação da ordem de serviço, é eficaz.

Os autores sugerem a criação de indicadores para quantificar e qualificar as reclamações, bem como aprofundar os estudos em relação aos problemas enfrentados pela Empresa $\mathrm{K}$ e suas devidas ações corretivas para obtenção da melhoria continua. Recomenda-se também um maior aprofundamento teórico sobre a influência da alta direção na disseminação da cultura da qualidade na organização. Por outro lado, em se tratando de um trabalho de pesquisa, se 
referenda tal proposição mercê da literatura trabalhada na construção deste artigo.

\section{REFERÊNCIAS}

ALBRECHT, Karl. Serviços com Qualidade: a vantagem competitiva. São Paulo: Makron Books, 1992.

CASTELLS, Manuel. A sociedade em rede. São Paulo: Paz e Terra, 1999. FITZSIMMONS, James A. E FITZSIMMONS, Mona J. - Administração de serviços: operações, estratégia e tecnologia de informação / 2 ed. - Porto Alegre: Bookman, 2000.

\section{FLEURY}

IDEC (Instituto Brasileiro de Defesa ao Consumidor) <http://www.idec.org.br/> acessado em 25 de fevereiro de 2015.

JURAN, J.M. 1904 - A qualidade desde o projeto: novos passos para o planejamento da qualidade em produtos e serviços. Tradução de Nivaldo Montingelle Jr. - São Paulo: Pioneira, 1992.

LAKATOS, Eva Maria; Maria de Andrade Marconi. Metodologia do trabalho científico: procedimento básico, pesquisa bibliográfica, projetos e relatórios, publicações e trabalhos científicos, - 6ª edição São Paulo: Atlas, 2001.

LAS CASAS, Alexandre L. - Qualidade total em serviços: conceitos, casos práticos. $2^{\circ}$ Edição - São Paulo - Atlas, 1997.

LIMA, S. M. V.; BRESSAN, C. L. Mudança organizacional: uma introdução. Mudança organizacional: teoria e gestão. Rio de Janeiro: FGV, 2003.

MALHOTRA, Naresh. Introdução à pesquisa de marketing. São Paulo: Prentice Hall, 2005.

MIGUEL, Paulo A. C. e SALOMI, Gilberto E. - Uma revisão dos modelos para medição da qualidade em serviços. Revista Produção V. 14 n.1, 2004.

MINTZBERG, H; LAMPEL, J.; QUINN, J. B.; GHOSHAL, S. - O Processo da Estratégia: Conceitos e casos selecionados. - Porto Alegre - Ed. Artmed, 2003.

MORAES, Paulo E. S. - Estratégia de Pesquisa sobre gestão da qualidade e da inovação tecnológica: o caso de serrarias do polo madeireiro de Telêmaco Borba, PR. - Tese apresentada ao programa de pós-graduação em 
engenharia florestal do Setor de Ciências Agrárias da Universidade Federal do Parará. - Curitiba, 2007.

MORAES, Paulo E. S.; FRANCO, Maura R. e SILVA, Guilherme R. S. S. Ensaio sobre a insustentável leveza do conceito de qualidade. Revista Qualidade Emergente, volume 1, n. 1; 3-12 - 2010.

NADLER, David A. e TUSHMAN, Michael L. - Beyond the charismatic leader: leadership and organizational change. California Management Review, vol. 32, Winter - 1990.

OLIVEIRA, Djalma P.R. - Administração de processos: conceitos, metodologia, práticas. 4ª ed. São Paulo: Atlas, 2011.

PALADINI, Edson P. - Gestão estratégica da qualidade: princípios, métodos e processos - $2^{\circ}$ ed. - São Paulo: Atlas, 2009.

PETERS, T. J. e AUSTIN, N. - Apassion for excellence. London: HarperCollins, 1994. 16

PORRAS, J. I. e ROBERTSON; . Organizational development: theory, practice and research. In: DUNNETTE, M. D.; HOUGH, L. M. (Orgs.). Handbook of Industrial and organizational Psychology Consulting Psychologists Press: Palo Alto California, 2003.

SCHEMENNER, Roger W. - Administração de operações em serviço. Tradução Lenke Peres. - São Paulo: Ed. Futura, 1999.

SEBRAE (Serviço Brasileiro de Apoio às Micro e Pequenas Empresas). $<$ http://www.sebrae.com.br/uf/goias/indicadores-das-mpe/classificaoempresarial> Acessado em 06 de fevereiro de 2015.

SLACK, Nigel et all. Administração da produção. São Paulo: Atlas, 2002.

SELLTIZ, C.; WRIGHTSMAN, L.S., COOK, S.W., KIDDER, L.H. Métodos de pesquisa nas relações sociais - Delineamentos de pesquisa. Tradução Maria M. H. d'Oliveira, Miriam M. Del Rey. $2^{\underline{a}}$ ed. - São Paulo: EPU, 1987.

ZEITHAML, Valarie A. e BERRY, Leonard L. A conceptual model de service quality and its implications for future research. Journal of Marketing, 1985.

ROBBINS, Stephen Paul - Administração: mudanças e perspectivas - São Paulo: Saraiva. 2000.

WEICK, K. E. e QUINN, R. E. Organizational Changeand Development. Annual Review of Psychology, 1999. 